\title{
Economia Liberal de Base Escrava: colônias, fazendas e racionalis- mo econômico no Rio de Janeiro (1840 - 1850)
}

\author{
Slavery Liberal Economy: colonies, plantations and economical rationalism in Rio de Janeiro (1840 \\ - 1850)
}

Gabriel de Azevedo Maraschin.

Como citar esse artigo. Maraschin

GA. Economia Liberal de Base Escrava: colônias, fazendas e racionalismo econômico no Rio de Janeiro $(1840$ - 1850). Revista Mosaico. 2014 Jan./Jun.; 05 (1): 05-10.

\begin{abstract}
Resumo
O objetivo deste trabalho é investigar a integração entre a organização da produção de abastecimento de gêneros de mercado interno com os de exportação na província fluminense entre 1840 e 1860 . Tal pesquisa é feita a partir da perspectiva de que a produção econômica nesse período resulta do avanço da economia de abastecimento na primeira metade do século XIX combinada com o avanço do latifúndio cafeeiro no recorte cronológico estudado. Palavras-Chave: Integração Econômica. Economia de Abastecimento. Mercado Interno.
\end{abstract}

\begin{abstract}
This article's objective means to investigate the integration between economic supply production and exporting rural producing in Rio de Janeiro by the years of 1840 to 1850 . This research was made by the perspective that economical production of this time is the result of intense supply economy development in the first half of XIX' sentry combined with the development of coffee production in the chronological period studied. Keywords: Economical integration. Supply economy. Domestic Market.
\end{abstract}

\section{Introdução}

Trabalhar a dinâmica do mercado de abastecimento do Rio de Janeiro oitocentista tem sido um trabalho árduo e de interessante destaque na historia econômica fluminense nos últimos anos. Além disso, a historiografia sobre a colonização no Brasil Império tem ou mantido sua produção tradicional sobre a imagem do imigrante ocupante das terras paulistas em substituição ao trabalho escravo, ou estudos de caso que mostram a colonização fluminense já como algo diferenciado, pautado na ocupação da terra devoluta pelo imigrante europeu.

Este trabalho visa traçar um paralelo, com intuito de contribuir para o debate, sobre a relação existente entre os programas de colonização fluminenses entre os anos de 1840 e 1850, concomitantes com a reorganização das relações de produção de abastecimento, que se destacavam juntamente com o crescimento econômico oriundo da expansão da produção do café. Vale ressaltar que esse artigo é limitado, praticamente um ensaio, pois se trata de uma pesquisa ainda em início de desenvolvimento, tendo avanço gradual e constantemente em diálogo com as discussões feitas em congressos e seminários.

A metodologia a ser utilizada está na observação sobre as tentativas de construções de colônias dentro do Rio de Janeiro como forma de ocupação territorial, introdução da mão de obra livre, aperfeiçoamento e ampliação das áreas de cultivo de gêneros de primeira e segunda necessidade, além de ampliarem as fronteiras do café. Sendo assim, as razões da colonização variavam desde a ocupação territorial até a formação de espaços de cultivos de gêneros de abastecimento para ampliação das relações econômicas em torno do Município Neutro.

A colonização existente nesse período seria um momento histórico próprio, portanto diferente daquele que buscava introduzir a força de trabalho livre em substituição da escrava que ocorreria em momentos finais do império. Ela seria uma forma integrada de produção, não dependente da grande lavoura, voltada para a ocupação da terra e a produção de gêneros de abastecimento.

As leituras sobre Dale Tomich e o conceito de 
Segunda Escravidão são interessantes ao tratarem da inserção do Império do Brasil enquanto base do fortalecimento capitalista do século XIX, desencadeando um processo de modernização econômica em sua sociedade. Entretanto, não nos interessa, em um primeiro momento, contribuir para o debate sobre a posição brasileira no mercado global nos oitocentos, mas sim extrair os caminhos que o desenvolvimento deste conceito nos expõe.

Dessa forma, existe a aproximação com a perspectiva de Modo de Produção, que se difere do conceito acima devido à busca pela compreensão da inserção brasileira na economia - mundo, mas de acordo com a organização produtiva peculiar ao Brasil. É claro que é preciso frisar que os debates em torno do modo de produção ou diminuíram drasticamente, ou cessaram mediante os avanços de outras vertentes historiográficas em finais de 1970 e ao longo de 1980 (além da própria perspectiva marxista), principalmente quando dele se desenvolveu a chamada teoria da dependência, nas décadas de 1950 e 1960.

Todavia, é preciso ressaltar que:

Modo de produção e formação social, [são] compreendidos respectivamente no conjunto, na natureza e no interrelacionamento de suas categorias básicas, como, por exemplo, relações de produção, forças produtivas, classes sociais, luta de classes, consciência de classe, etc.. ${ }^{1}$

Então, a problemática desse trabalho paira sobre as seguintes questões: como funcionaria a organização do mercado interno em um país que se enquadre na perspectiva do modo de produção? Como se dá a ocupação da terra pelos pequenos proprietários e o funcionamento da força de trabalho familiar (se é que existiu)? Como são estruturadas as relações pessoais e políticas dentro desse modo de produção que rompe com seu passado colonial, mas que mantêm em vigor suas principais estruturas econômicas?

\section{A integração como forma de manutenção da ordem escrava}

Trabalhar com o conceito de "segunda escravidão" é levar em consideração a função econômica da escravidão americana de acordo com o desenvolvimento do capitalismo ocidental e como ele se desenvolveu a partir desse modo de produção ao longo do século XIX. Como diria Edward Baptist, a "Primeira Escravidão produziu bens de luxo como açúcar e tabaco para o consumo conspícuo de elites (...). A Segunda Escravidão produziu mercadorias-chave (...) para os florescentes mercados industriais (...)"2. Essas "mercadorias-chave"

1 LAPA, José Roberto Amaral. Introdução ao redimensionamento do debate. In.: LAPA, José Roberto AMARAL (org.). Modos de produção e a realidade brasileira. Ed.: Vozes ltda. Petrópolis, Rio de Janeiro, 1980, p. 15. Grifos do autor:

2 BAPTIST, Edward E. A Segunda Escravidão e a Primeira República Americana. Almanack Guarulhos, $\mathrm{n}^{\circ} 5,1^{\circ}$ semestre de 2013 , p.p. $10-11$ estariam concentradas na produção de café, no Brasil, açúcar, em Cuba e algodão, nos EUA.

Entretanto, a segunda escravidão é conceito surgido na década de 1980 e debatido no Brasil principalmente a partir dos historiadores coniventes da visão de modo de produção escravista ou modo de produção colonial. Sendo assim, a organização das forças produtivas brasileiras é, sob essa ótica, resultado de fatores internos pressionados por fatores externos.

Porém, os fatores internos, que não são negligenciados, vêm das relações dos diversos segmentos sociais brasileiros e seus projetos políticos, ou seja, são ações de agentes históricos que atuam concomitantemente aos fatores externos que pairam sobre essa mesma sociedade. Em suma, para que o escravismo brasileiro no século XIX consiga abranger cada vez mais espaço na economia mundo, é necessário existir uma ordem interna capaz de fornecer os subsídios necessários para que essa produção escravocrata ganhe tamanha magnitude.

Ao analisarmos o conceito de bloco histórico, de Antonio Gramsci, torna-se mais fácil compreendermos a necessidade de se fazer a relação acima citada. Para ele, o bloco histórico é "unidade entre a natureza e o espírito (...), unidade dos contrários e dos distintos", ${ }^{3}$ ou seja, um espaço temporal onde estaria construída uma ordem social que conseguisse ampliar suas formas de pensamento e ações para dentro dos diversos grupos sociais, organizando um modo de produção que se propõe como hegemônico nessa mesma sociedade.

Com isso, se a organização estrutural da lavoura cafeeira como principal ponto de exportação é oriunda de um projeto político racional, logo é preciso encontrar a organização econômica interna que venha a suprir esse modelo de produtividade agrário-exportador. Alcir Lenharo já nos alerta para "a necessidade de formulação de um corpo conceitual novo que de conta do caráter mercantil dessa economia de subsistência aberta e voltada para o mercado interno". 4

Para ele, a economia de abastecimento no CentroSul de Minas Gerais foi fator fundamental da estruturação da nova organização econômica brasileira, tendo como um de seus resultados a construção do Vale do Paraíba. A economia de subsistência não seria, portanto, aquela vulgarizada na pequena propriedade com o trabalho livre, mas sim um campo específico de enriquecimento e escalada social de proprietários escravistas que buscavam constantemente reconhecimento político.

Entretanto, o historiador, mesmo de forma crítica, rebate a visão do que seria a função básica que a subsistência exerce sobre a prática da exportação, onde na "etapa de expansão das exportações, restringem-

3 GRAMSCI, Antonio Cadernos do Cárcere: Maquiavel, notas sobre o Estado e a política. Edição de Carlos Nelson Coutinho com Marco Aurélio Nogueira e Luiz Sérgio Henriques. Ed · Civilização Brasileira, Rio de Janeiro, $2007,3^{\circ}$ volume, p. 26.

4 LENHARO, Alcir. Tropas da moderação: 0 abastecimento da Corte na formação política do Brasil: 1808 - 1842. Ed.: Biblioteca Carioca, 1992, Rio de Janeiro, $2^{\mathrm{a}}$ edição, p. 26. 
se a área e os recursos produtivos da economia de subsistência, carreados para o outro setor produtivo (...)". Entretanto, quando o movimento das exportações encolhe, os "(...) fatores produtivos transferem-se para a economia de subsistência que tende a inflar". 5

Essa visão clássica sobre a economia de subsistência nos traz uma impressão, alertada por Lenharo, de que esse segmento serve como uma espécie de "bolsão", estando sempre na retaguarda do setor exportador. A partir daí, ou imaginamos a produção do mercado interno como algo totalmente organizado apenas para o suprimento da grande lavoura, ou esse mercado é colocado em segundo plano pelas autoridades governamentais, tendo o setor exportador como termômetro a medir o crescimento econômico nacional.

Ora, essa relação de dependência do mercado interno sobre a produção para exportação diminui a importância que a organização das forças produtivas em uma economia de abastecimento possui e que "deixa a história brasileira mais complexa, dinâmica e menos simplista". ${ }^{6}$ Dessa forma, é importante observar a colonização da década de 1840 como um processo inicial de estimulo à construção dessa economia interna. Antes mesmo do recorte estudado, em 1835, o ministro José Ignácio Borges já apontava essa necessidade:

\begin{abstract}
Dois meios portanto à nossa disposição; um de promover a população indígena, outro o de convidar a emigração estrangeira (...). Quanto ao $2^{\circ}$, convém observar que o que até agora se há praticado com a aquisição de Colonos, não tem produzidoosbons efeitos, queoutros paísestemalcançado(...). É portanto evidente nossa prosperidade dependendo de maior numero de braços trabalhadores, e este numero da certeza de que no Brasil há segurança de vida e prosperidade (...). ${ }^{7}$
\end{abstract}

Trazer colonos para a construção de lavouras e, consequentemente, mantê-los na terra já nos mostra que a vinda deles possui um propósito produtivo, ou seja, eles não habitaram essas terras para viver de uma produção excedente, mas sim de produtos voltados ao mercado interno. Essas mercadorias seriam não apenas gêneros agrícolas como também produtos manufaturados e a colonização seria intermediada por empresas em constante contato com o governo imperial.

A Província de Santa Catarina tem atraído as vistas de numerosas pessoas para estabelecimentos semelhantes. Por Decreto de 10 deAgosto do ano passado autorizou o Governo a organização de uma Companhia Belgo-Brasileira para formar com Colonos de qualquer pais da Europa, Estabelecimentos de agricultura, indústria, e mineração na mencionada Província, debaixo das Condições anexas ao mencionado Decreto (...). ${ }^{8}$

5 Idem, Ibidem, p. 26

6 CAMPOS, Pedro Henrique Pedreira. A história do abastecimento e a historiografia brasileira. In. CAMPOS, Pedro Henrique Pedreira; GUIMARÃES, Carlos Gabriel; PIÑEIRO, Théo Lobarinhas (orgs.). Ensaios de História Econômico - Social: séculos XIX e XX. Niterói, Editora da UFF, 2012, (orgs.)

7 Relatório do Ministro do Império, 1835, p. 8 .

8 Idem, 1843 , p. 34
Se retomarmos a citação de Lenharo, a crítica que o historiador faz é a de que a produção de subsistência ainda é uma produção mercantil dependente do excedente de produção. Ou seja, pelo fato de a massa populacional ser escrava, não há um mercado consumidor massificado, o que faz com que os proprietários comprem aquela quantia necessária para sua sobrevivência. Dessa forma, a produção de abastecimento estaria limitada à comercialização do que sobra da produção, capaz de suprir as necessidades.

Para ele é justamente o contrário, essa produção começa a deixar de se sustentar com base no excedente e passa a utilizar a sua terra para produção exclusiva da comercialização interna, mais racional e lucrativa, incluindo a elevação de status político para seus proprietários. Levando essa análise para o processo de colonização aqui estudado, podemos perceber que a ocupação está seguindo critérios econômicos racionalizados, com intermediação empresarial de indivíduos que, aparentemente, possuem negócios especializados em transporte de força de trabalho onde "superabundam operários de diversos ofícios". 9

A produção, por sua vez, seria aquela voltada para o cultivo de hortaliças e especiarias específicas, sendo estas para a exportação em pequeno volume. Além disso, como pudemos ver nas citações acima, esse seria o primeiro momento até que resultassem em ganhos suficientes para que os colonos iniciassem atividades manufatureiras típicas de seus países para dentro do mercado brasileiro e, até mesmo, se organizarem para o "fabrico do açúcar (...), a cultura do café e finalmente a do tabaco". ${ }^{10}$

$\mathrm{Ou}$ seja, a colonização estaria voltada para a ocupação da terra, para o suprimento de mercado interno, mas também estaria organizada de acordo com o modelo exportador. Nada foi encontrado, nas fontes, a respeito da posse de escravos por parte dos colonos, mas a organização econômica das colônias também "girava em torno de núcleos exportadores, isto é, visavam atender às necessidades de um mercado interno definido pela dinâmica dos setores exportadores". ${ }^{11}$

Essa ocupação da terra também envolve a relação entre a força de trabalho livre e escrava. Como ponto principal, a colonização com a vinda de imigrantes preferencialmente europeus tinha como objetivo preparar o terreno das terras devolutas no interior das províncias para o trabalho livre, uma vez que o trabalho escravo estaria com seus dias contados.

Concluirei este Artigo, repetindo que o Governo prepara uma Proposta sobre Colonização estrangeira, e sesmarias, ou datas de terras, materiais tão intimamente conexos

9 Idem, Ibidem, p. 35

10 Idem, Ibidem, p. 35

11 SALLES, Ricardo; MARQUESE, Rafael. A escravidão no Brasil oitocentista: história e historiografia. In.: SALLES, Ricardo; MARQUESE, Rafael (orgs.). Escravidão e Capitalismo Histórico no século XIX: Brasil, Cuba e Estados Unidos. Seminário promovido pela rede local da Segunda Escravidão em parceria com o Laboratório de Estudos sobre o Brasil e o Sistema Mundial (Lab - Mundi/USP), realizado na Universidade de São Paulo em 16 de setembro de 2013, p. 101. 
no seu conceito, que uma não pode separar-se da outra; e de tanta importância, quanto é a necessidade de braços, cuja falha ameaça de morte a nossa Industria (...). Tem-se pretendido em diversos projetos atrair mormente capitais, e população, quando conviria antes promover a emigração de trabalhadores pobres, moços, e robustos: nada se tem temido pelos capitais existentes, empenhando-se por isso muito em seu aumento, quando estes se podem considerar ameaçados de eminente desfalque: parece ter-se entendido que os braços existentes não sofrerão míngua com a cessação do tráfico de Africanos, resolvida em Tratados que força é respeitar, quando deve recear-se que sua redução será tal, e tão rápida, que acabrunhará nossa Indústria. ${ }^{12}$

Além disso, atrair "trabalhadores pobres, moções e robustos" se enquadra no plano de trazer para as terras devolutas jovem força de trabalho barata que, mediante sua precariedade na realidade europeia, vê na vinda ao Brasil a chance de melhoria. Pelo menos na primeira metade da década de 1840 , o intuito era "convidar trabalhadores pobres, que substituam os braços, que dentro de pouco tempo hão de falecer-nos", já que os "capitalistas" que "são dignos da proteção do Governo"13 não seriam capazes de entrar no lugar do lavrador escravo.

A partir de 1845, a fala dos ministros sobre a colonização ganha corpo. As ações governamentais não conseguiram bons frutos e, no Rio de Janeiro, apenas uma colônia foi colocada como destaque a partir de 1846, que é a Colônia do Córrego Seco, ou Petrópolis. Ademais, os colonos que vinham, em sua maioria, não conseguiram se fixar na terra ou por não terem conseguido recursos suficientes para pagar suas dívidas com o Estado ou debandaram da terra frente à falta de infraestrutura fornecida pelo governo.

Surge, então, o apelo ao consórcio com a iniciativa privada, aqueles empresários ditos capitalistas, para investimento de seu capital na atração de mais imigrantes europeus. A exigência por intermediação está acompanhada de processo de reestruturação sobre a posse da terra, onde entram em questão as possibilidades de acesso que os colonos podem ter em possuírem propriedade fundiária.

Formou-se, cada vez mais, demanda política e econômica para o preenchimento dos espaços interioranos das províncias, expondo verdadeiros intuitos civilizatórios, sobre o papel do colono na formação econômica brasileira, responsáveis por "desenvolver o espírito de empresas, a navegação, o comércio, a indústria, as artes; precisamos portanto de capitalistas, de fabricantes, de operários, de artífices, de jornaleiros (...) de braços livres (...)". ${ }^{14}$

É preciso ressaltar que esse recorte cronológico apresenta, como principal característica, uma sociedade civil em construção, com escassas organizações sociais feitas para garantir interesses corporativos e que,

2 Relatório do Ministro do Império, 1843, p.p. 35 - 36

13 Idem, p. 36.

14 Idem, 1847 , p. 42 . Grifo meu. futuramente, venham a ganhar corpo social e político. Diversos trabalhos de historiadores expõem casos tanto de associações civis já consolidadas e formadoras de quadros políticos, como de grupos sociais dependentes de cargos públicos que, apenas futuramente, conseguiram acumular experiência político-administrativa para se desvencilharem da sociedade política e formarem seus grupamentos dentro da sociedade civil.

Com a proibição definitiva do comércio transatlântico de escravos, em 1850, há de se aproveitar a iniciativa colonizadora como ponto de pauta nas discussões sobre o acesso a terra:

Não sendo possível que a colonização europeia se promova
de uma maneira vantajosa sem um Ato Legislativo que regule
a concessão e venda das terras devolutas; e pendendo de
discussão no Senado um Projeto de Lei sobre colonização e
venda de terras, que convenientemente emendado ministrará
os meios de dar a este importantíssimo objeto todo o
desenvolvimento de que carece, deliberou o Governo remeter
a uma Comissão de pessoas de conhecida ilustração topos os
esclarecimentos que a Repartição a meu cargo podia ministrar,
a fim de que habilitada com esses dados a ajuizar melhor das
necessidades do país, propunha ela as medidas que no seu
conceito parecerem mais profícuas para obter-se aquele fim.
Tem-se esta Comissão, a cujos trabalhos tenho presidido,
efetivamente ocupado deles, e aguarda o Governo as medidas
que ela houver de poder para deliberar como convier". ${ }^{15}$

Este relatório feito pelo Visconde de Mont'Alegre, em janeiro de 1850, antecede a Lei de Terras, mas já apresenta propostas de regulamentação da colonização que definam as condições para que o colono adquira propriedade. Ao mesmo tempo, a economia cafeeira entra em maior vigor, expandindo suas fronteiras, é o momento de redistribuição da população escrava no Brasil e da redefinição da posse sobre a propriedade fundiária.

Apesar de tanto o mercado interno, quanto a ocupação territorial terem como referencia a grande lavoura exportadora, campo de sobrevivência do império, falar em uma dependência econômica seria, novamente, reduzir a importância dessa economia. Quando há a demonstração de a produção de abastecimento estar sob resguardo do latifúndio, tal relação se dá pelo propósito da integração econômica, não necessariamente havendo dependência.

Sob os estudos de Ilmar de Mattos e Alcir Lenharo, essa integração fica mais esclarecida quando compreendemos que o incentivo ao mercado interno por parte do governo imperial também é seguido de desenvolver e aproximar o corpo de "cidadãos ativos" 16 para as instancias do jogo político. As colônias, por sua vez, dinamizam relações econômicas internacionais e que estimulam a formação de companhias que fortaleciam a experiência político-econômica desse

15 Idem, 1850 , p.p. $39-40$. 16 MATTOS, Ilmar Rohlof
$3^{\mathrm{a}}$ edição, São Paulo, 1990. 
Estado em sua fase restrita.

Além disso, de acordo com a Tabela I, houve um conjunto de impostos que concentrava parte da produção destinada ao mercado interno presentes nos chamados
Diversos ramos da Renda Provincial. Relacionando a quantidade de arrecadação acumulada por esses impostos com a do chamado Dízimo, destinado exclusivamente aos produtos de exportação, é possível compreender

Tabela 1. Participação dos impostos relacionados ao mercado interno (dados aproximados)

\begin{tabular}{|l|r|r|r|r|r|r|r|r|r|r|}
\hline & \multicolumn{2}{|c|}{ TABELA I } \\
\hline Anosticipação dos impostos relacionados a mercado interno (dados aproximados) \\
\hline
\end{tabular}

Fonte. mapas de Rendas Provinciais disponíveis nos Relatórios de Presidente de Provincia.

que a economia da província fluminense possuía em seu projeto a valorização do desenvolvimento desse tipo de propriedade.

Podemos reparar que, ao longo do recorte cronológico, a quantidade arrecadada de impostos diretamente ligados ao mercado interno é bastante plural, já que cada tributo corresponde a um campo na produtividade interna diferenciado. Entretanto, é preciso esclarecer que as fontes utilizadas para essa tabela abrangem os tributos de uma maneira geral, sendo preciso analisar os mapas de rendas municipais para se ter maior visão sobre a dimensão da produtividade de abastecimento, assim como a produtividade das colônias em seus respectivos municípios.

Todavia, analisar os dados acima permite, ao menos, observar a arrecadação feita nos caminhos percorridos nas estradas até o destino final dessa produtividade, presente, em grande parte, no Município Neutro. Sendo assim, de acordo com a tabela, o total desses tributos diretamente ligados ao mercado interno chegam à soma de aproximadamente $20,50 \%$ de toda a arrecadação provincial, excluindo o dízimo.

Obviamente, a listagem tributária apresentada acima está resumida, uma vez que o dízimo era cobrado sobre outros produtos, tais como algodão e açúcar, além dos diversos ramos também conterem em sua pauta tributos envolvendo outros assuntos, tais como imposto sobre bilhetes de loterias, prédios urbanos, etc. Além disso, essa tabela não contempla toda a produção interna, uma vez que esse período era marcado por intensas dificuldades tanto na coleta tributária, quanto na manutenção da infraestrutura provincial para que os registros de produtos, assim como o fisco, fossem realizados de maneira adequada.

Dessa forma, a tabela auxilia em uma compreensão do todo, mas não fecha a questão. Mediante os relatos nas fontes apresentadas juntamente com a historiografia de abastecimento, é possível imaginar que o fluxo desses produtos transcendia o preparo do governo em medilo, pois possui uma lógica diferente da dos produtos destinados ao Dízimo.

\section{Conclusão}

Essa análise procurou expor, dentro de seus limites, o funcionamento da ocupação territorial no interior das províncias como forma de articulação do mercado interno voltado para o resguardo do investimento da grande lavoura escravista. Dessa forma, a presença de colonos, sobretudo europeus, ocuparia uma terra em nova perspectiva, de força de trabalho livre e empreendedora, que criaria os meios necessários para melhorar os meios produtivos e organizar as forças produtivas internas em prol da valorização de gêneros de abastecimento concomitantemente ao expansionismo do café.

As colônias, nesse ínterim, seriam a principal alternativa de ocupação da terra em um momento de desenvolvimento do modo de produção. Sua produção estaria tanto para o enriquecimento dessa economia de abastecimento, crucial para o governo saquarema em aumentar o domínio pleno do governo em combate aos poderes regionais, quanto para o desenvolvimento da civilização idealizada por esses conservadores, que enxergavam no trabalhador europeu a chance de desenvolver o Brasil em outros setores da economia 
tendo, em sua lógica, o Rio de Janeiro como principal laboratório.

Todavia, frente às falhas em diversas colônias projetadas e até mesmo instaladas, a colonização fluminense mostrou-se como um experimento pouco frutífero, principalmente com o sucesso do projeto colonizador da província de São Paulo. Observar a colonização paulista, que ganha destaque após 1870, é, também, observar o período da decadência da força de trabalho escrava, assim como da lavoura fluminense e, consequentemente, da gradual desconstrução da política saquarema.

A expansão da fronteira agrícola cafeeira para áreas mais interioranas de São Paulo, tal como a da Mogiana, em Ribeirão Preto ${ }^{17}$ seguiram o modelo de desenvolvimento experimentado no Rio de Janeiro, com a expansão das plantações em paralelo com a expansão da malha ferroviária. Essa malha, além de escoar produção, serviu para colocar os imigrantes que chegavam diretamente na lavoura e em locais novos de produtividade e de organização de grupos políticos em oposição ao centralismo conservador, que incluíam $\mathrm{o}$ acesso à terra (apesar de em regime de colonato) e ao desenvolvimento manufatureiro, objetivos esses que, como vimos, estavam enquadrados no projeto colonizador fluminense.

Por fim, ao fazermos essa breve comparação, podemos concluir que o projeto sofreu fortes obstáculos principalmente devido ao seu contexto histórico-social. Frente a um Rio de Janeiro em construção que estava englobado na ampliação do próprio Estado brasileiro, as colônias europeias eram a alternativa da construção de uma economia dinamizada e fortemente civilizatória, mas que enfrentava barreiras quase que indestrutíveis pelo próprio modo de produção que envolvia a economia cafeeira fluminense entre os anos de 1840 e 1850.

\section{Referências}

\section{Documentação}

Relatórios dos Ministros do Império de 1840 a 1850: Center of Research Libraries, área Eletronic Resources, sessão Brazilian Government Documents: www.crl.edu.

Relatórios dos Presidentes de Provincia do Rio de Janeiro de 1840 a 1850 : Center of Research Libraries, área Eletronic Resources, sessão Brazilian Government Documents: www.crl.edu.

\section{Bibliográficas}

BAPTIST, Edward E. A Segunda Escravidão e a Primeira República Americana. Almanack Guarulhos, n ${ }^{\circ} 5,1^{\circ}$ semestre de 2013.

CAMPOS, Pedro Henrique Pedreira. A história do abastecimento e a historiografia brasileira. In.: CAMPOS, Pedro Henrique Pedreira;
GUIMARÃES, Carlos Gabriel; PIÑEIRO, Théo Lobarinhas (orgs.). Ensaios de História Econômico - Social: séculos XIX e XX. Niterói, Editora da UFF, 2012.

GRAMSCI, Antonio. Cadernos do Cárcere: Maquiavel, notas sobre o Estado e a política. Edição de Carlos Nelson Coutinho com Marco Aurélio Nogueira e Luiz Sérgio Henriques. Ed.: Civilização Brasileira, Rio de Janeiro, 2007, $3^{\circ}$ volume.

LANZA, André Luiz; LAMOUNIER, Maria Lúcia. Café, imigrantes e empresas no nordeste de São Paulo (Ribeirão Preto, 1890 - 1930). In: Revista História Econômica e História das Empresas, vol. 17, n. 2, 2014.

LAPA, José Roberto Amaral. Introdução ao redimensionamento do debate. In.: LAPA, José Roberto AMARAL (org.). Modos de produção e a realidade brasileira. Ed.: Vozes ltda. Petrópolis, Rio de Janeiro, 1980.

LENHARO, Alcir. Tropas da moderação: o abastecimento da Corte na formação política do Brasil: 1808 - 1842. Ed.: Biblioteca Carioca, 1992, Rio de Janeiro, $2^{\mathrm{a}}$ edição.

MATTOS, Ilmar Rohloff. $O$ Tempo Saquarema: a formação do Estado Imperial. Ed.: HUCITEC, $3^{\mathrm{a}}$ edição, São Paulo, 1990.

SALLES, Ricardo; MARQUESE, Rafael. A escravidão no Brasil oitocentista: história e historiografia. In.: SALLES, Ricardo; MARQUESE, Rafael (orgs.) Escravidão e Capitalismo Histórico no século XIX: Brasil, Cuba e Estados Unidos. Seminário promovido pela rede local da Segunda Escravidão em parceria com o Laboratório de Estudos sobre o Brasil e o Sistema Mundial (Lab - Mundi/USP), realizado na Universidade de São Paulo em 16 de setembro de 2013

TOMICH, Dale W. Trough the Prism of Slavery: Labor, Capital, and World Economy. INC. USA Rowman \& Littlefield Publishers, 2004. 